\title{
False killer whale (Pseudorca crassidens) echolocation and acoustic disruption: implications for longline bycatch and depredation
}

\author{
T.A. Mooney, A.F. Pacini, and P.E. Nachtigall
}

\begin{abstract}
False killer whales (Pseudorca crassidens (Owen, 1846)) depredate fish caught by the North Pacific pelagic longline fishery, resulting in loss of target species catch and the whales themselves becoming bycaught. This incidental take of false killer whales exceeds sustainable levels. In an effort to address a potential solution to reducing this depredation and bycatch, we tested an acoustic device designed to deter false killer whales from approaching longlines by reducing the whales' echolocation performance capabilities. The device produced a series of complex, broadband signals (1-250 kHz) at high intensity levels (up to $182 \mathrm{~dB}$ ). In the experiment, a trained false killer whale was asked to detect a target in the presence or absence of the acoustic device. Baseline performance capabilities were $95 \%$ correct responses. Initially, the device reduced the whale's echolocation performance to chance levels. However, subsequent sessions demonstrated improvement in echolocation performance up to $85 \%$. This improvement was likely a result of behaviorally adapting to the task and a decrease in the source level of the echolocation "disruptor". The results underscore the challenges in using acoustic devices to reduce depredation and bycatch, and demonstrate the need for concern regarding anthropogenic noise levels and effects on odontocete echolocation capabilities.
\end{abstract}

Résumé : Les fausses orques (Pseudorca crassidens (Owen, 1856)) pillent les poissons attrapés par la pêche à la palangre dans le Pacifique Nord, ce qui entraîne une perte des espèces ciblées et la capture accessoire des fausses orques ellesmêmes. Cette capture accidentelle de fausses orques dépasse les niveaux viables. Dans le but de trouver une solution potentielle pour réduire ce pillage et ces captures accessoires, nous avons évalué un appareil acoustique destiné à décourager les fausses orques de s'approcher des palangres en réduisant les capacités de performance de l'écholocation chez les fausses orques. L'appareil produit une série de signaux complexes à large bande (1-250 kHz) à de fortes intensités (jusqu'à $182 \mathrm{~dB}$ ). Durant l'expérience, une fausse orque entraînée a été appelée à détecter une cible en présence ou en l'absence de l'appareil acoustique. Les capacités de performance de base comportaient $95 \%$ de réussites. Au début, l'appareil réduisait la performance d'écholocation de l'orque à des niveaux aléatoires. Cependant, aux sessions subséquentes, il y a eu une amélioration de l'écholocation de jusqu'à $85 \%$. Cette amélioration est vraisemblablement le résultat d'une adaptation comportementale à la tâche et d'une diminution du niveau source du « disrupteur » d'écholocation. Ces résultats soulignent les défis qu'il y a à utiliser des dispositifs acoustiques pour réduire le pillage et les captures accessoires et ils démontrent la nécessité de se préoccuper des niveaux de bruits anthropiques et de leurs effets sur les capacités d'écholocation des odontocètes.

[Traduit par la Rédaction]

\section{Introduction}

It is well documented that marine mammals interact with fisheries around the world, and this widespread relationship between fishers and marine mammals rarely seem to benefit both parties. For example, dolphin-tuna associations in the Eastern Tropical Pacific have been utilized to locate and identify tuna schools for harvesting, which at one time resulted in substantial herding and incidental catch of dolphin

Received 20 January 2009. Accepted 27 May 2009. Published on the NRC Research Press Web site at cjz.nrc.ca on 31 July 2009.

T.A. Mooney, ${ }^{1,2}$ A.F. Pacini, and P.E. Nachtigall. Department of Zoology and Hawai'i Institute of Marine Biology (HIMB), University of Hawai‘i, P.O. Box 1106, Kailua, HI 96734 USA.

${ }^{1}$ Corresponding author (e-mail: amooney@whoi.edu).

${ }^{2}$ Present address: Biology Department, Woods Hole

Oceanographic Institution, Marine Research Facility - MS \#50, 266 Woods Hole Road, Woods Hole, MA 02543, USA. species (NRC 1992). Both pinnipeds and cetaceans have learned to remove target fish from various fishing operations such as aquaculture facilities (Quick et al. 2004), gillnets (Cox et al. 2003), longlines (Thode et al. 2007), and trawlers (Broadhurst 1998). This often results in damage to fishing gear and harvestable fish. As a consequence of these and other marine mammal - fisheries interactions, two primary challenges can be established: (1) loss of target catch for fisherman, which may have deleterious economic and social consequences (Gilman et al. 2006), and (2) incidental catch of marine mammals (bycatch), reducing populations and resulting in potential ecological changes (Read et al. 2006). Thus, mitigation measures are often suggested to reduce both the loss of target catch and bycatch rates of marine mammals.

Situations that present a particularly important need to reduce these interactions include populations or species of marine mammals that are of limited size. In this case, further reduction in numbers can threaten a population's survival, perhaps leading to extinction (Slooten et al. 2006; Turvey et 
al. 2007). The population of false killer whales (Pseudorca crassidens (Owen, 1846)) in Hawaiian waters has considerable interaction with longline fisheries (Baird and Gorgone 2005); whales are removing target catch, such as tunas, from the longlines (depredation) and as a result, are being occasionally caught on the longline hooks (Gilman et al. 2006). Fisherman may lose a substantial amount of marketable fish and whales may be seriously injured or killed in this process. The rate of bycatch exceeds the "potential biological removal" (PBR) set for the population by the National Oceanic and Atmospheric Administration National Marine Fisheries Service (NOAA-NMFS) resulting in a stock of "strategic" importance (Caretta et al. 2006), indicating that such bycatch rates could result in a decline of the population size.

Methods to reduce marine-mammal bycatch depend on the fishery but may include $(i)$ reducing fishing seasons or regions (Murray et al. 2000), (ii) establishing marine protected areas (MPAs) with fishery regulations (Dawson and Slooten 1993), (iii) modifying the gear to prevent entanglement (Mooney et al. 2004, 2007), or (iv) deterring animals from approaching the fishing area (Quick et al. 2004). Limiting fishing capabilities through regulation or MPAs may have the negative consequences of reducing the economic intake of fisherman and some social components of fishing communities. However, developing technology that reduces bycatch but maintains target species catch has obvious benefits to both fisheries and ecosystems.

We investigated an acoustic tool proposed to deter false killer whales from approaching longlines, thus reducing depredation and bycatch. The device, a SaveWave Long-line Saver, was designed to emit sounds hypothesized to reduce echolocation capabilities, one of the primary sensory modalities of odontocete marine mammals. This, in turn, was proposed to discourage false killer whales from attempting to remove target catch from longline gear. Similar acoustic devices such as pingers have reduced harbor porpoise (Phocoena phocoena (L., 1758)) bycatch in gillnet fisheries (Kraus et al. 1997) by presumably alerting the animal of the net's presence. In longline fisheries the goal of an acoustic device would likely not be a warning of gear presence but rather to disrupt the animal's depredative behavior. The efficacy of an acoustic device or disruptive tool has not yet been addressed in reducing marine mammal bycatch in longline fisheries. The goals of this experiment were to (i) characterize the sounds produced by the device and (ii) determine the tool's efficacy in reducing false killer whale echolocation performance, thus evaluating its potential to reduce depredation and bycatch.

\section{Materials and methods}

\section{Animal subject and background}

The study animal was an approximately 30-year-old female false killer whale $(4.1 \mathrm{~m}$ and $528.4 \mathrm{~kg})$, housed in the open-water sea pens off the HIMB's Coconut Island, Kaneohe Bay, O`ahu, Hawai'i, USA. The animal has had considerable experience with echolocation research, including target detection tasks similar to the experiment presented here (see Nachtigall and Supin 2008). Experiments were conducted in March and April of 2007, over 15 experimen- tal sessions, each consisting of 50 trials. All sessions were designed around a target detection task in the presence, or lack, of an acoustic device that emitted broadband acoustic signals. The device, a SaveWave Long-line Saver (Delft, the Netherlands), was intended to reduce false killer whale depredation and bycatch on longline fishing sets by producing a loud, broadband acoustic signal. This signal was proposed to decrease a false killer whale's echolocation performance abilities, and consequently, deter them from approaching a longline, attempting to depredate it, and becoming hooked. We sought to investigate the capability of this device in "jamming" a false killer whale's sonar in a series of target detection experiments.

\section{Experimental procedure}

The experiments were conducted across two experimental pens (Fig. 1). The animal was tested in the first pen, which was supported by floats, bounded a wire net, and was $8 \mathrm{~m} \times$ $10 \mathrm{~m}$ in size (1). At the far end of this enclosure was an equipment shack (2), which housed the electronics for the experiment and an operator. A second "enclosure", $7 \mathrm{~m} \times$ $10 \mathrm{~m}$ in area (3), was used to suspend the echolocation targets. This structure was without the wire net, and the supporting floats were positioned to the side to prevent any potential acoustic reflections during the echolocation task. A trainer (4) sat along the side of the first pen to provide instructions and monitor the animal during the experiment. A hoop-opening $55 \mathrm{~cm}$ in diameter was fixed between the two pens, which served as a hoop station (5) for the animal during the echolocation task, so that it could be positioned in pen 1 , but required to echolocate into the free-field of pen 2. Near the hoop station was an underwater camera (6), which allowed the animal's behavior to be monitored from the shack. One metre in front of the hoop was an acoustical baffle (7), which could be raised or lowered and prevented the animal from echolocating into the target pen until the proper time. Just behind the baffle was an acoustically transparent plastic screen that did not preclude sound transmission but inhibited the whale from seeing the target. A Reson 4013 hydrophone (8; Slangerup, Denmark) was positioned $2 \mathrm{~m}$ in front of the hoop and $1.34 \mathrm{~cm}$ in front of the whale to detect the animal's echolocation pulses. An aluminum cylinder, $3.8 \mathrm{~cm}$ in diameter and $12.7 \mathrm{~cm}$ in length, served as the target (9) for which the animal was trained to echolocate for and was hung $8 \mathrm{~m}$ in front of the animal from an aluminum pipe and pulley, the pipe spanning the width of the target pen. The cylinder was hung from a thin monofilament line and could be pulled out of, or lowered into, the water. Near the hoop station was a response ball (10) mounted above the water surface, serving as a target-present response indicator. Except for early training sessions and the last session, the Long-line Saver (11) was suspended $8 \mathrm{~m}$ from the whale and $1 \mathrm{~m}$ to the side of the target.

Each session began with the false killer whale stationing near the trainer. Upon a cue from the trainer, the animal would leave the surface station and swim to the hoop station, $1.5 \mathrm{~m}$ below the water's surface. When the animal was in position, the target would either be gently lowered into the water (for a target-present trial), or lowered and then raised (for a target-absent trial). The acoustic baffle was then lowered allowing a free and direct path between whale 
Fig. 1. The experimental setup for the target detection task of a false killer whale (Pseudorca crassidens). The various components are referred to in the text.

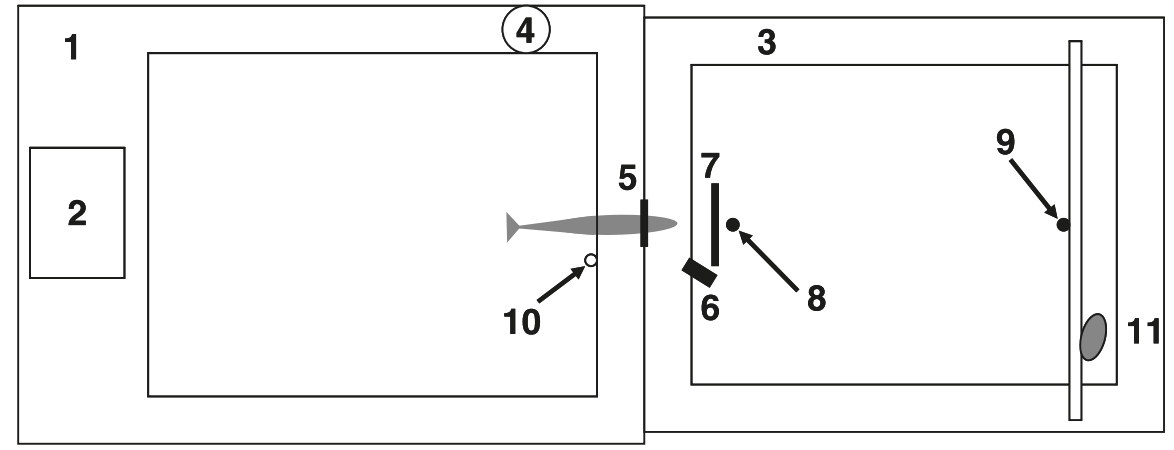

and target. This was also the whale's cue to echolocate. A go/no-go paradigm was employed in which the go response was associated with target present and the no-go was associated with target absent (Schusterman 1980). If the whale detected a target, it would back out of the hoop and touch the response ball with its rostrum (a go). If the whale did not detect the target, the animal remained in the hoop for approximately $5 \mathrm{~s}$ (a no-go), until the trainer blew a whistle recalling the animal. Only correctly indentifying target presence (a hit) or absence (correct rejection) was rewarded with fish, and both present and absent trials were equally rewarded. Incorrect responses included false alarms (responding when no target was present) or a miss (failure to respond when the target was present).

The Long-line Saver was designed to reduce false killer whale echolocation capabilities, thus the experiment was designed to determine if the device would reduce the echolocation performance of detecting the aluminum target. Two initial sessions were devoted to establishing the animal's baseline performance level, without the acoustic device in the water. Two subsequent sessions were run with the device in the water but turned off, with the device being placed $8 \mathrm{~m}$ from the whale, $1.5 \mathrm{~m}$ to the side of the target. A session was then run with the device on for the entire session. The sessions were then broken up so that the acoustic device was off for 10 trials, on for 20 trials, and off for 10 trials. Five "warm-up" and "cool-down" trials preceded and followed the experimental trials. These ABBA sessions were run until the animal's performance level stabilized again, four sessions later. A session was then run with the device in the water but off, ensuring that the whale's detection baseline performance was consistent. Then, to determine how distance and reduced sound pressure levels (SPLs) might affect detection performance, the device was moved $30 \mathrm{~m}$ from the whale, but still in line with the target. All sessions were 50 trials, consisting of 5 blocks of 10 trials. Each block was randomized to target present versus absent following a Gellermann series (Gellermann 1933).

\section{Acoustic signals}

The Long-line Saver was half-spherical in shape, with a diameter of $38.1 \mathrm{~cm}$ and weighing $24 \mathrm{~kg}$ (Fig. 2). The acoustic signals emitted by the SaveWave device were a complicated assortment varied up- and down-sweeps, pure tones, and harmonics. We calibrated the sound levels emitted before the experiment on three separate days with essen- tially the same results. The Long-line Saver device was hung off a dock at $1 \mathrm{~m}$ depth in the open seawater environment of Kaneohe Bay. Signals were received $2 \mathrm{~m}$ from the source using a calibrated Biomon 8235 hydrophone (sensitivity $-182 \pm 2 \mathrm{~dB}$ up to $300 \mathrm{kHz}$; Santa Barbara, California, USA), which was connected to a Krohn-Hite 3364 filter (Brockton, Massachusetts, USA) for anti-alias bandpass filtering $(300 \mathrm{~Hz}$ to $250 \mathrm{kHz})$. Ten $1 \mathrm{~s}$ files were recorded from three different directions (front, side, and back) on each of the three calibration days to get a general estimate of the directionality of the device. Files were recorded using a custom LabView program working with a National Instruments DAQ card (6062E; Austin, Texas, USA) implemented into a laptop computer. Signals were sampled at a rate of $512 \mathrm{kHz}$. The Long-line Saver sounds were extremely broadband (from 1 to $250 \mathrm{kHz}$ ), but signals were not recorded above $250 \mathrm{kHz}$, as this was considered well beyond the range of hearing for false killer whales and other odontocetes (Thomas et al. 1988; Yuen et al. 2005). These sounds were referenced to calibrated pure tones of 20, 40, 60, 80, 100, and $120 \mathrm{kHz}$, produced by a Wavetek function generator (Everett, Washington, USA) connected to a Reson 4040 transducer and recorded in the same manner as the Long-line Saver signals above. All signals were monitored as they were recorded using a Tektronix TDS 1002 oscilloscope (Richarson, Texas, USA).

The recorded signals were assessed off-line using CoolEdit (Adobe Systems, San Jose, California, USA) and MatLab (MathWorks, Natick, Massachusetts, USA) programs. Portions were selected from each of the pure tones and the broadband SaveWave noise files and analyzed with a 2048point fast Fourier transform (FFT). The peak values of the FFTs were compared between tones and the noise files to determine the peak intensity of the Long-line Saver. Before the experiment, the device produced a relatively intense source level $(\mathrm{SL}=182 \mathrm{~dB}$ re: $1 \mu \mathrm{Pa}$ ) from the forward direction, but signals dropped off to the side and back at 174 and $164 \mathrm{~dB}$, respectively. After the experiment and approximately $25 \mathrm{~h}$ of use, the Long-line Saver device dropped off in sound pressure level to $162 \mathrm{~dB}$ peak intensity at the source and in the center of the front-facing beam. Peak received levels at the animal were $164 \mathrm{~dB}$.

\section{Data collection and analysis}

The primary data collected were based on the performance of the false killer whale in the echolocation task. Cor- 
Fig. 2. (a) Sample spectrograms of the various acoustic signals produced by the acoustic deterrent. (b) The Long-line Saver hung in sea water for calibration. $(c)$ A diagram for the suggested use and deployment of the device.
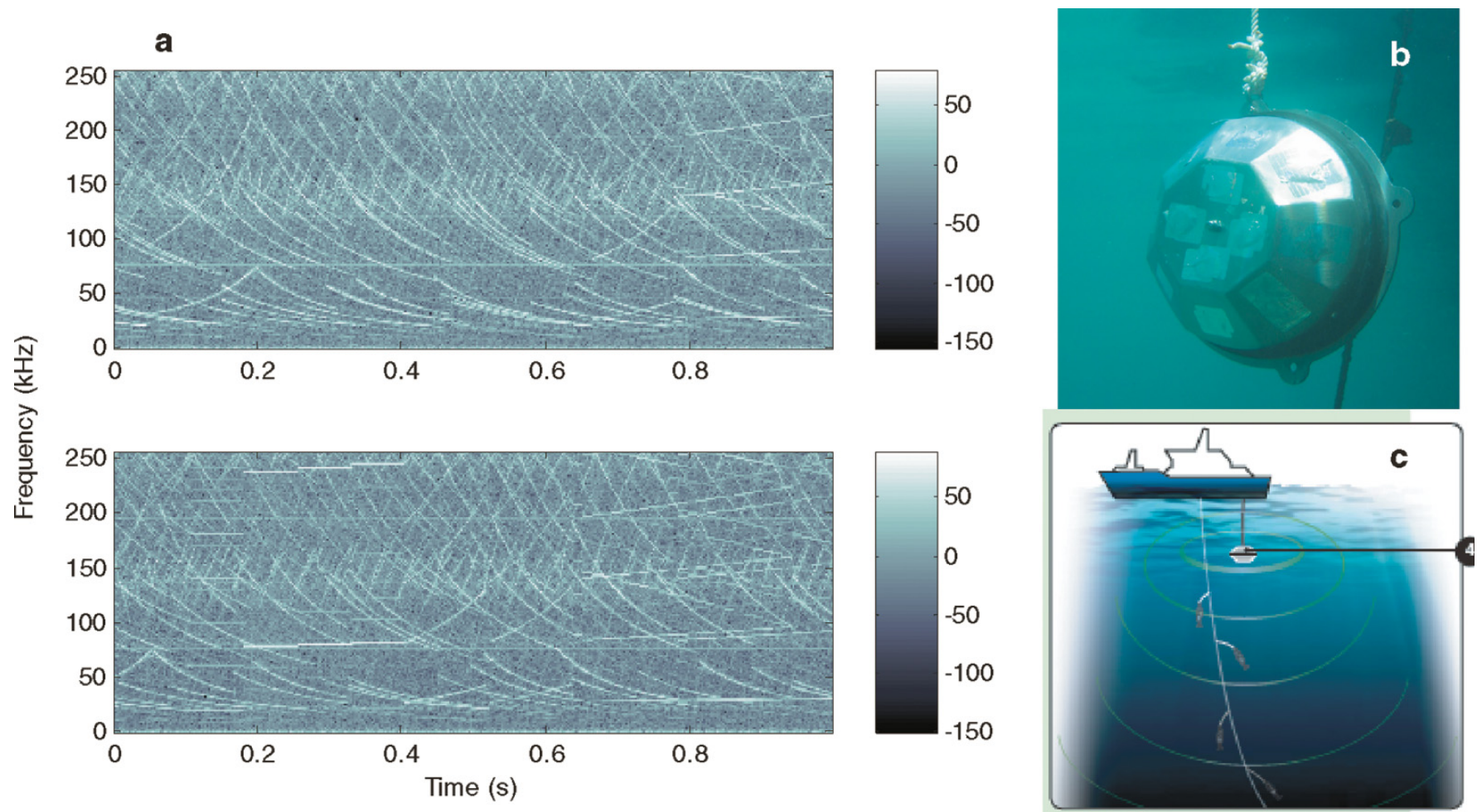

rect responses (hits and correct rejections) were measured against incorrect response (misses and false alarms) and compared using a two-tailed $t$ test. A number of complimentary parameters were collected for each trial to measure additional effects of the Long-line Saver. Because the Saver might be considered an acoustic harassment device, several of the parameters were designed to assess the acoustic device's influence on the animal's behavior. This included the delay (s) from when the trainer sent the whale to the hoop to when it actually stationed in the hoop, the number of echolocation clicks used, the latency of time (s) for the whale to respond (only in target present responses), and any overt behavioral alterations during the experiment. Within each category the variable was averaged and compared using a two-tailed $t$ test. The animal's behavior in the hoop and at the surface was video-recorded. Minitab and Excel softwares were used in the behavioral data analysis. All methods and animal care abided by national and university animal care guidelines (Institutional Animal Care and Use Committee (IACUC) Permit No. 93-005-13; National Academy of Sciences 1996).

\section{Results}

\section{Echolocation performance}

The experiment was initiated by establishing the false killer whale's baseline echolocation performance ability and ensuring that the percentage of correct responses was stable. Across the first four sessions, the animal demonstrated a mean $97 \%$ correct response rate $(\mathrm{SD}=1.15)$ to the presence and absence of the cylinder target (Fig. 3). For the first two sessions, the acoustic device was not yet suspended in the water and the animal responded $98 \%$ correct. The single errors in both sessions were misses. In the following two baseline sessions (3 and 4) the Long-line Saver was hung in its experimental position, but the sound was not turned on and the whale's performance was a similar $96 \%$. The acoustic device was kept in the water for the remainder of the experiment. The errors in these sessions were made within the first 5 trials of both sessions and 3 of the 4 errors were false alarms.

During session 5, the Long-line Saver was turned on as the animal first entered the hoop station for the first echolocation trial of the session. The sound then remained on for the entire session (50 trials; approximately $1 \mathrm{~h}$ ), including all subsequent target presence or absence trials. The animal's performance dropped off to $46 \%$ for this session. Eleven errors were false alarms and 16 errors were misses. We then returned to a session with the Long-line Saver off for the session's entirety. With the device off, the whale responded correctly for $96 \%$ of the trials, reaffirming its baseline performance capabilities.

We then switched to an ABBA format of the trial order within sessions to hopefully reduce frustration of the animal in the apparently difficult task of target detection when the Long-line Saver was emitting sound. During this portion of the experiment, the animal's detection performance improved significantly when the Long-line Saver was on (Fig. 4), although performance was never at the level of trials without sound. In the first session, the animal correctly identified target presence or absence at $60 \%$ with the Longline Saver on and $95 \%$ with it off. Of the incorrect responses when the device was on, $87.5 \%$ were false alarms. For the remaining three sessions, the animal's performance leveled off at $85 \%$ for sound-on trials and $98 \%$ for sound-off trials. 
Fig. 3. Target detection performance displayed in percent correct responses of the false killer whale (Pseudorca crassidens) for sessions where the acoustic deterrent was on (solid) or off (open). The Long-line Saver was suspended $8 \mathrm{~m}$ from the animal during its echolocation task except for the last session when the device was placed $30 \mathrm{~m}$ from the whale.

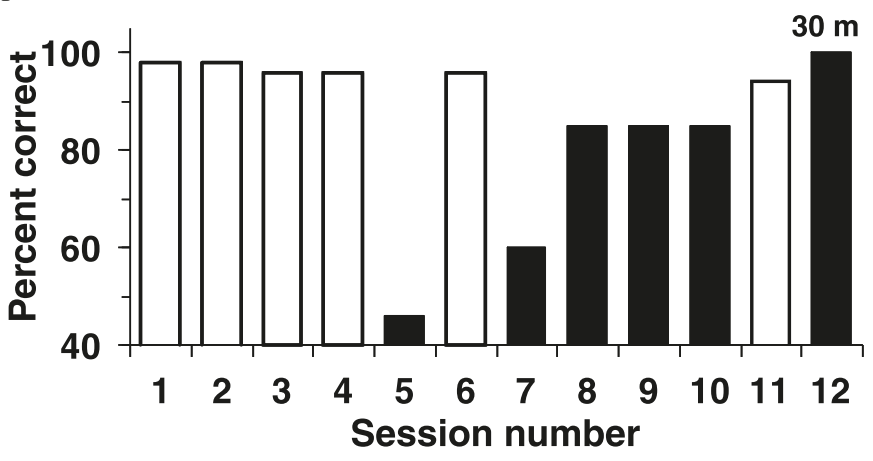

Fig. 4. Target detection performance in correct responses of the false killer whale (Pseudorca crassidens) for sessions in ABBA format, as well as the mean performance of those sessions.

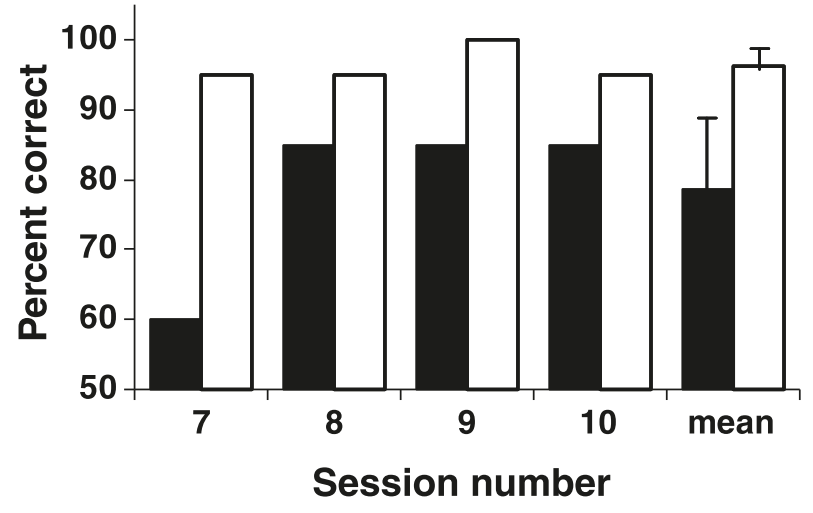

Over the course of these four sessions, the animal detected target presence or absence significantly better when the Long-line Saver was off (mean on $=78.8 \%$, mean off $=$ 96.2\%; two-tailed $t$ test, $p=0.03$ ).

After performance stabilized, we returned to a full session with the Long-line Saver off to re-establish baseline capabilities, and the whale demonstrated $94 \%$ correct responses. In the final session we moved the device $30 \mathrm{~m}$ from the animal, turned the acoustic device on, and returned to the original echolocation task. The animal was $100 \%$ correct in identifying the presence or absence of the target.

\section{Receiver Operating Characteristics}

The animal's hits (correct detections) and false alarm probabilities were plotted in receiver operating characteristic (ROC) curves (Figs. 5a-5c) to asses how the whale might make decisions of detecting the target within background noise (the acoustic disruption device). As noted, when the sound was off the animal's hit rate was very high, near $100 \%$, and the probability of false alarms was relatively low $(\leq 20 \%$; Figs. $5 a, 5 c)$. Such clear responses indicate the ease at which the whale could detect the target in the standard situation. However, when the acoustic disruption device was turned on, it was obvious that the echolocation detec-
Fig. 5. Receiver operating characteristic (ROC) graphs for the false killer whale (Pseudorca crassidens) performing the echolocation task. (a) All data when acoustic Long-line Saver was in the water. Circle indicates session 5 when sound was on for the entirety. Squares indicate sessions 7-10 when the device was on for an ABBA format. Diamond indicates a summary of all trials when the acoustic device was on. Triangle indicates all sessions when the device was off. (b) Sessions 5 and 7 when the acoustic device was on. Squares indicate 10 trial blocks. Large square (i.e., $60 \%$ hit rate and $20 \%$ false alarms) indicates last block and apparent improvement in correct responses. Triangle indicates the summation of data. (c) Sessions 1-4, 6, and 11 when acoustic device was off. Times indicate 10 trial blocks. Square indicates the summation of data.
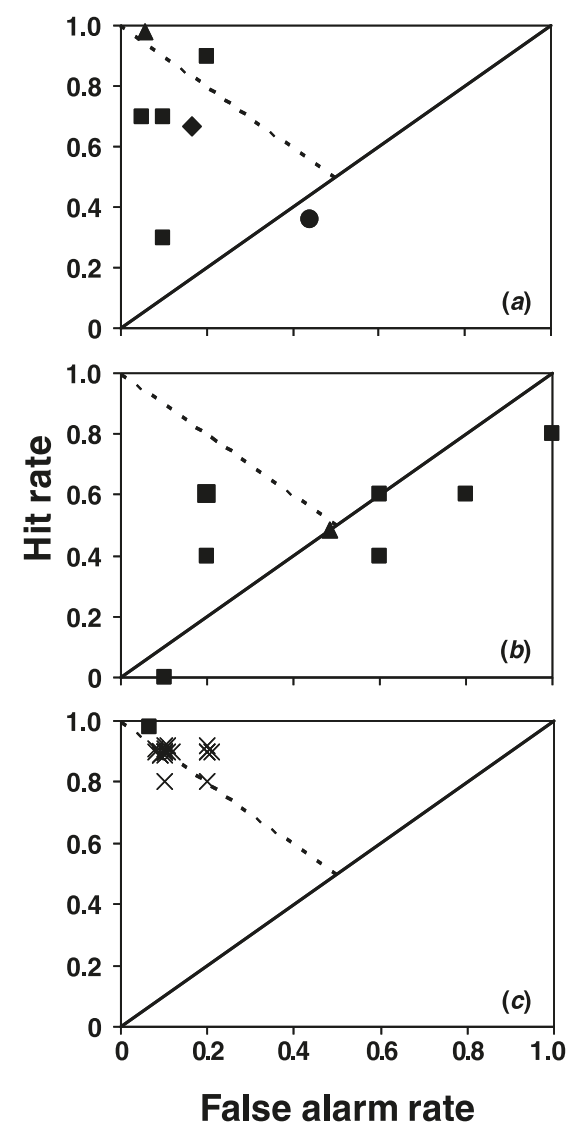

tion task became more difficult. Hit rates initially dropped below $40 \%$ and false alarm rates increased to near $50 \%$ (Fig. 5a), indicating that the animal became less "conservative" and was apparently lowering its detection threshold or guessing. However, as sessions continued, the false alarm rate dropped and the hit rate increased, as the whale improved and returned to a more conservative approach.

For a more detailed look at the decisions made when the acoustic device was first turned on, we analyzed the first two sessions with the device on, broken up into 10-trial blocks (Fig. 5b). Notably, the animal's false alarm and hit rate changed substantially throughout the sessions. Nearly all hovered around the major diagonal, indicating the animal's likelihood of a correct response was near chance thus supporting that the whale was guessing. Or by changing strategies from conservative to "liberal", the whale could 
Table 1. Two-tailed $t$ tests for behavioral alterations of the false killer whale (Pseudorca crassidens) associated with the use of the Long-line Saver acoustic device.

\begin{tabular}{llcccc}
\hline Behavioral parameter & Long-line Saver status & Trials $(n)$ & Mean value & SD & $p$ \\
\hline Latency to hoop (s) & On & 36 & 5.175 & 0.522 & $<0.001$ \\
& Off & 149 & 4.772 & 0.380 & \\
Delay (s) & On & 82 & 9.79 & 1.13 & ND \\
& Off & 173 & 9.93 & 1.34 & \\
Number of clicks & On & 128 & 21.1 & 10.4 & $<0.001$ \\
& Off & 297 & 12.63 & 6.70 & \\
\hline
\end{tabular}

Note: ND, no difference.

Fig. 6. Behavioral responses of the false killer whale (Pseudorca crassidens) during sessions when the Long-line Saver was on. Responses noted include latency (s) to the echolocation-hoop station, delay (s) to respond to target presence, and number of echolocation clicks used per trial. Large stars indicate significant differences between groups.
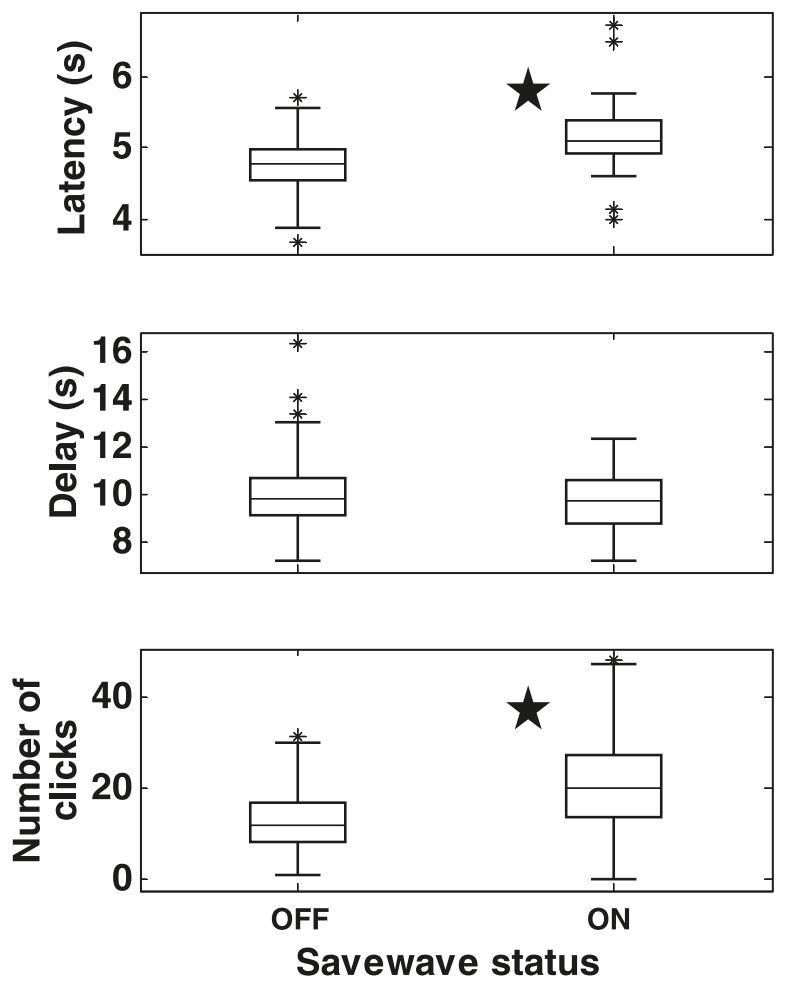

have been searching for a strategy to improve her chances of correct detection. While overall, the whale's strategy across the two sessions was $50 \%$ for both hits and false alarm, the last trial block (large square) showed improvement to $60 \%$ hit rate and $20 \%$ false alarms.

\section{Behavior}

In addition to echolocation capabilities, we monitored several behavioral parameters to address potential reactions to the acoustic device. The animal did not demonstrate any significant behavioral alterations in the presence of the acoustic stimulus. The animal also did not increase its swimming time (delay; s) from the trainer station to the echolocation-hoop station (Table 1, Fig. 6). However, the false killer whale did take significantly longer to decide target presence when the Long-line Saver was turned on. Additionally, the animal used a significantly greater number of echolocation clicks when the acoustic device was on.

\section{Discussion}

The SaveWave Long-line Saver did work to significantly reduce the echolocation performance of an experienced and well-practiced false killer whale. The increased number of echolocation clicks used and latency of time to decide target presence or absence indicate that the device apparently made the echolocation task more difficult. However, the animal's performance in the presence of the device improved over the duration of the experiment, from $46 \%$ (or essentially guessing) to a respectable $85 \%$. This indicates that either the false killer whale devised a strategy to improve its target detection capabilities in noise, or that the decrease in sound pressure levels over time allowed for easier target detection, or both, contributed to the animal's improved performance.

Unfortunately the decrease in sound pressure levels over a relatively short period of time ( $\sim 25 \mathrm{~h}$ of use) confounds the results of the experiment somewhat because the decrease makes it difficult to discern whether the whale's improvement was from learning or reduction in sound. However, moving the device $30 \mathrm{~m}$ away from the animal (typically the device was $8 \mathrm{~m}$ away) obviously decreased the received sound levels at the animal and, consequently, the whale was $100 \%$ correct in identifying target presence or absence during that session. Thus, the output of the device and received levels at target animals have a crucial effect on echolocation performance and the effectiveness of the Long-line Saver. This may be crucial in many longline situations with gear tens of kilometres in length (Gilman et al. 2006). If the acoustic device has a limited radius of effectiveness, then its use in deterring depredation may well also be restricted. Perhaps a better acoustic solution might be the implementation of smaller, but loud acoustic devices fixed repeatedly on the longline to cover the line effectively.

The decrease in source level (SL) also indicates how the device may have worked to reduce echolocation performance. At the start of the experiment, when the Long-line Saver was operating at higher SLs, the device effectively reduced echolocation performance to chance level. As SLs apparently decreased but signal types remained consistent, performance improved. Thus, it was not the complex acoustic signals that were the basis of reducing the echolocation performance, but more likely, the masking of the echoes by the intense noise. Consequently, the sound pressure (or received level) and frequency spectrum of the acoustic disruptormasker may be more important than the type of signal itself. 
Interestingly, echolocation performance was reduced slightly (85\%) even when the device's source levels had dropped. Bottlenose dolphins (Tursiops truncatus (Montagu, 1821)) demonstrate similar decreases in echolocation performance in the presence of background noise (Au and Penner 1981). These decreases in performance occur at noise spectrum levels that are above background but not necessarily significantly higher in intensity (Au 1993). This is because masker levels are relative to the echo level, thus the lower the echo level, the lower the effective masker-noise level may be. This raises concern for animals which echolocate and forage in environments that have high levels of anthropogenically induced background noise. The animals' echo detection may be reduced by the surrounding noise levels. This is particularly true if the animal is echolocating on targets that may not have strong echo returns (i.e., squid, monofilament nylon line, or fishing hooks), making certain items difficult to detect.

Detecting the target in noise also revealed that when the task was difficult and the target was not easy to detect, the animal seemed to vary its strategy from high false alarms and high hit rates, to low false alarms but lower hit rates. While this may simply have been guessing during a trying task, this may also indicate that the animal was "searching" for a strategy which would yield greater success. Furthermore, the incidence of less conservative, higher false alarm rates indicates that this false killer whale might have attempted a fairly liberal target detection strategy. This is quite different than what has been shown typical for bottlenose dolphins, which tend to be conservative and not allow false alarm rates to rise above a certain level ( $\mathrm{Au}$ and Snyder 1980). Research along similar lines with other odontocetes that live in varying niches may find further evidence for differing decision strategies. Furthermore, the study whale is well experienced in experimental investigations. Different strategies may be used by wild or younger animals inhabiting a complex, pelagic environment.

This device was intended to be suspended from the side of a boat and broadcast sound into the ocean environment to deter false killer whales (Fig. 2). Sound intensity levels were apparently engineered to be relatively high (up to $182 \mathrm{~dB}$ peak energy). The device might be considered more of an "acoustic harassment" tool, rather than a deterrent (Quick et al. 2004). Received levels at our false killer whale were approximately no more than $164 \mathrm{~dB}$ peak energy for relatively short durations of time (4-6 s), which are well below any physiological effects (Nachtigall et al. 2004; Finneran et al. 2005; Mooney et al. 2009). The animal also did not demonstrate any overt behavioral modifications to approaching the hoop station, where the maximum received levels were measured. However, this animal was well trained in many experimental procedures such as this echolocation task, and obvious behavioral reactions would not have been expected. More dramatic reactions to acoustic harassment devices would be expected and have been noted in wild, naïve animals (Quick et al. 2004).

The complexities and relative ineffectiveness of this wellengineered acoustic device underscores the challenges related to deterring odontocetes from depredation and becoming caught on longlines. The simple mass of this device unfortunately causes it to be difficult to handle and operate.
Furthermore, applying a single device from a boat and expecting acoustic disruption on longline kilometres away does not seem to be a realistic means of reducing echolocation performance, depredation, or bycatch. However, it seems that the masking of echolocation signals reduces echolocation performance. Thus, smaller, louder, and more numerous devices might cause such effects and should be tested. As these devices would likely be costly and difficult to implement and maintain, government support would likely enhance implementation if the devices prove successful in echolocation disruption. Mechanistic devices that shroud catch and reduce depredation should also be explored for their detection possibilities in captive research settings. It is obvious that devices to decrease bycatch and depredation must meet certain characteristics, including that they actually succeed, are relatively easy to disseminate and implement, are cost effective, and do not decrease the catch rates of target species (McPherson 2003; Gilman et al. 2006). However, as seen here and in other studies (Cox et al. 2001; Gilman et al. 2006), cetacean species often habituate to certain devices. Such modifications and assessments are often seen in animal foraging strategies (Pyke et al. 1977; Lima and Bednekoff 1999). Solutions to these fisheries-related issues will probably need to be equally flexible. It is likely multiple tools, including acoustic and mechanistic, should be applied to deter depredation and bycatch. To achieve these goals researchers, fisherman, and regulatory agencies will need to work closely to find suitable resolutions.

\section{Acknowledgements}

We gratefully acknowledge the Western Pacific Regional Fishery Management Council for their encouragement and funding of the project, as well as Rick van Lent and Wouter van Dam of SaveWave for lending us the Long-line Saver. Additional funding came from Robert Gisiner of the US Office of Naval Research for research grant No. N00014.05.1.07.38 to P.N. Marlee Breese, Stephanie Vlachos, Dera Look, and Chris Quintos all participated in the data collection. Whitlow Au provided advice in signal analysis. Michelle Yuen and Geoff McPherson contributed valuable input on the subject. Work was conducted under a Scientific Research Permit to Take Marine Mammals from NOAA-NMFS Office of Protected Resources Permit No. 978-1567-0 and a Research Protocol approved by the University of Hawai'i IACUC Permit No. 93-005-13 to P.N. This is HIMB contribution No. 1351 and School of Ocean and Earth Science and Technology (SOEST) contribution No. 7760.

\section{References}

Au, W.W.L. 1993. The sonar of dolphins. Springer-Verlag, New York.

Au, W.W.L., and Penner, R.H. 1981. Target detection in noise by echolocating Atlantic bottlenose dolphins. J. Acoust. Soc. Am. 70(3): 687-693. doi:10.1121/1.386931.

Au, W.W.L., and Snyder, K. 1980. Long-range target detection in open waters by an echolocating Atlantic bottlenose dolphin (Tursiops truncatus). J. Acoust. Soc. Am. 68(4): 1077-1084. doi:10.1121/1.384993.

Baird, R.W., and Gorgone, A. 2005. False killer whale dorsal fin disfigurements as a possible indicator of long-line fishery inter- 
actions in Hawaiian waters. Pac. Sci. 59(4): 593-601. doi:10. 1353/psc.2005.0042.

Broadhurst, M.K. 1998. Bottlenose dolphins, Tursiops truncatus, removing by-catch from prawn-trawl codends during fishing in New South Wales, Australia. Mar. Fish. Rev. 60(3): 9-14.

Caretta, J.V., Forney, K.A., Muto, M.M., Barlow, J., Hanson, B., and Lowry, M.S. 2006. U.S. Pacific marine mammal stock assessments: 2005. NOAA Tech. Memo. NMFS-SWFSC-388.

Cox, T.M., Read, A.J., Solow, A.J., and Tregenza, N. 2001. Will harbour porpoises (Phocoena phocoena) habituate to pingers? J. Cetacean Res. Manag. 3(1): 81-86.

Cox, T.M., Read, A.J., Swanner, D.W., Urian, K.W., and Waples, D.M. 2003. Behavioral responses of bottlenose dolphins, Tursiops truncatus, to gillnets and acoustic alarms. Biol. Conserv. 115(2): 203-212. doi:10.1016/S0006-3207(03)00108-3.

Dawson, S., and Slooten, E. 1993. Conservation of Hector's dolphins: the case and process which led to establishment of the Banks Peninsula Marine Mammal Sanctuary. Aquat. Conserv. 3(3): 207-221. doi:10.1002/aqc.3270030305.

Finneran, J.J., Carder, D.A., Schlundt, C.E., and Ridgway, S.H. 2005. Temporary threshold shift in bottlenose dolphins (Tursiops truncatus) exposed to mid-frequency tones. J. Acoust. Soc. Am. 118(4): 2696-2705. doi:10.1121/1.2032087. PMID:16266189.

Gellermann, L. 1933. Chance orders of alternating stimuli in visual discrimination experiments. J. Genet. Psychol. 42: 206-208.

Gilman, E., Brothers, N., McPherson, G., and Dalzell, P. 2006. A review of cetacean interactions with longline gear. J. Cetacean Res. Manag. 8(2): 215-223.

Kraus, S.D., Read, A.J., Solow, A.J., Baldwin, K., Spradlin, T., Anderson, E., and Williamson, J. 1997. Acoustic alarms reduce porpoise mortality. Nature (London), 388(6642): 525. doi:10. $1038 / 41451$.

Lima, S.L., and Bednekoff, P.A. 1999. Temporal variation in danger drives antipredator behavior: the predation risk allocation hypothesis. Am. Nat. 153(6): 649-659. doi:10.1086/303202.

McPherson, G. 2003. Reduction of interactions by toothed whales with fishing gear. Development and assessment of predation mitigation devices around longlines. Review of acoustic exposure and habituation to toothed whales. Milestone Progress Rep. No. 5. Fisheries Research and Development Corporation, Canberra, A.C.T., Australia.

Mooney, T.A., Nachtigall, P.E. and Au, W.W.L. 2004. Target strengths of a nylon monofilament and an acoustically enhanced gillnet: predictions of biosonar detection ranges. Aquat. Mamm. 30(2): 220-226. doi:10.1578/AM.30.2.2004.220.

Mooney, T.A., Au, W.W.L., Nachtigall, P.E., and Trippel, E.A. 2007. Acoustic and stiffness properties of gillnets as they relate to small cetacean bycatch. ICES J. Mar. Sci. 64(7): 1324-1332. doi:10.1093/icesjms/fsm135.

Mooney, T.A., Nachtigall, P.E., Breese, M., Vlachos, S., and Au, W.W.L. 2009. Predicting temporary threshold shifts in a bottlenose dolphin (Tursiops truncatus): the effects of noise level and duration. J. Acoust. Soc. Am. 125(3): 1816-1826. doi:10.1121/1. 3068456. PMID: 19275338.
Murray, K.T., Read, A.J., and Solow, A.J. 2000. The use of time/ area closures to reduce bycatches of harbour porpoises: lessons from the Gulf of Maine sink gillnet fishery. J. Cetacean Res. Manag. 2: 135-141.

Nachtigall, P.E., and Supin, A.Y. 2008. A false killer whale adjusts its hearing when it echolocates. J. Exp. Biol. 211(11): 17141718. doi:10.1242/jeb.013862. PMID:18490386.

Nachtigall, P.E., Supin, A.Y., Pawloski, J.L., and Au, W.W.L. 2004. Temporary threshold shifts after noise exposure in the bottlenose dolphin (Tursiops truncatus) measured using evoked auditory potentials. Mar. Mamm. Sci. 20(4): 673-687. doi:10. 1111/j.1748-7692.2004.tb01187.x.

National Academy of Sciences. 1996. Guide for the care and use of laboratory animals. National Academy Press, Washington, D.C.

NRC. 1992. Dolphins and the tuna industry. National Academies Press, Washington, D.C.

Pyke, G.H., Pulliam, H.R., and Charnov, E.L. 1977. Optimal foraging: a selective review of theory and tests. Q. Rev. Biol. 52(2): 137-154. doi:10.1086/409852.

Quick, N.J., Middlemas, S.J., and Armstrong, J.D. 2004. A survey of antipredator controls at marine salmon farms in Scotland. Aquaculture, 230(1-4): 169-180. doi:10.1016/S0044-8486(03) 00428-9.

Read, A.J., Drinker, P., and Northridge, S. 2006. Bycatch of marine mammals in U.S. and global fisheries. Conserv. Biol. 20(1): 163 169. doi:10.1111/j.1523-1739.2006.00338.x. PMID:16909669.

Schusterman, R.J. 1980. Behavioral methodology in echolocation by marine mammals. In Animal sonar systems. Edited by R.G. Bushnel and J.F. Fish. Plenum, New York. pp. 11-41.

Slooten, E., Dawson, S., Rayment, W., and Childerhouse, S. 2006. A new abundance estimate for Maui's dolphin: what does it mean for managing this critically endangered species? Conserv. Biol. 128(4): 576-581. doi:10.1016/j.biocon.2005.10.013.

Thode, A., Straley, J., Tiemann, C.O., Folkert, K., and O'Connell, V. 2007. Observations of potential acoustic cues that attract sperm whales to longline fishing in the Gulf of Alaska. J. Acoust. Soc. Am. 122(2): 1265-1277. doi:10.1121/1.2749450. PMID:17672672.

Thomas, J.A., Chun, N., Au, W.W.L., and Pugh, K. 1988. Underwater audiogram of a false killer whale (Pseudorca crassidens). J. Acoust. Soc. Am. 84(3): 936-940. doi:10.1121/1.396662. PMID:3183211.

Turvey, S.T., Pitman, R.L., Taylor, B., Barlow, J., Akamatsu, T., Barrett, L.A., Zhao, X., Reeves, R.R., Stewart, B.S., Wang, K., Wei, Z., Zhang, X., Pusser, L.T., Richlen, M., Brandon, J.R., and Wang, D. 2007. First human-caused extinction of a cetacean species? Biol. Lett. 3(5): 537-540. doi:10.1098/rsbl.2007.0292.

Yuen, M.M.L., Nachtigall, P.E., Breese, M., and Supin, A.Y. 2005. Behavioral and auditory evoked potential audiograms of a false killer whale (Pseudorca crassidens). J. Acoust. Soc. Am. 118(4): 2688-2695. doi:10.1121/1.2010350. PMID:16266188. 